\title{
CEREBRAL OXYGEN SUPPLY MONITORED BY NEAR INFRARED SPECTROSCOPY (NIRS) IN THE FIRST DAYS OF LIFE IN PRETERM INFANTS AFTER MATERNAL USE OF LABETOLOL
}

\author{
L. Thewissen ${ }^{1}$, L. Pistorius ${ }^{2}$, W. Baerts ${ }^{1}$, F. van Bel ${ }^{1}$, P. Lemmers ${ }^{1}$ \\ ${ }^{I}$ Neonatology, ${ }^{2}$ Perinatology, Wilhelmina Children's Hospital, University Medical Center Utrecht, Utrecht, \\ The Netherlands
}

Background and aims: The aim of management of severe preeclampsia is to improve neonatal outcome and to prevent maternal complications. Antihypertensive treatment improves maternal outcome but has the potential to be deleterious. Maternal hypertension and preeclampsia can cause fetal IUGR and brainsparing. Although effects are to be expected from maternal use of beta blockers, scarce information on neonatal cerebral hemodynamics is available. Labetolol-induced changes in blood pressure (MABP) may influence regional cerebral saturation $(\mathrm{rScO} 2)$.

Methods: 18 infants with GA $<32$ weeks, born after maternal use of labetolol (ML-group) were included and matched for GA, birth weight (BW) and gender (C-group).

Arterial oxygen saturation, MABP, heart rate (HR) and $\mathrm{rScO} 2$ were monitored and an average was calculated on day 1 and 2.

Results: GA, BW, respiratory support, use of inotropics and incidence of IVH did not differ between groups. Antenatal brainsparing was more prevalent in the ML-group $(\mathrm{P}<0.05)$. HR was significantly lower in the ML-group in the first 48 hours but was always within normal limits (144 BPM \pm 10.5 vs $152 \mathrm{BPM} \pm 10.7$, $\mathrm{p}<0.001$ ). MABP was not different at all time points. $\mathrm{rScO} 2$ was significantly higher in the ML group (68 \pm 10 vs $62 \pm 9, \mathrm{p}<0.001)$.

Conclusions: Despite lower HR in infants of preeclamptic mothers treated with labetolol cerebral oxygenation seems not to be compromised. Brainsparing seems to be associated with a higher oxygen delivery in the brain probably due to vasodilation and/or loss of autoregulatory ability of the cerebral vascular bed. 